Saudi Journal of Oral and Dental Research

Abbreviated Key Title: Saudi J Oral Dent Res

ISSN 2518-1300 (Print) |ISSN 2518-1297 (Online)

Scholars Middle East Publishers, Dubai, United Arab Emirates

Journal homepage: https://saudijournals.com/sjodr

\title{
Role of Placentrex in Dentistry and Oral and Maxillofacial Surgery: A Review
}

\author{
Dr. Mohammed Nishan*
}

Senior Resident, Department of Oral Medicine \& Radiology, Government Dental College, Kozhikode, Kerala, India

DOI: $10.36348 /$ sjodr.2020.v05i09.012

| Received: 04.09.2020 | Accepted: 14.09.2020 | Published: 19.09.2020

*Corresponding author: Dr. Mohammed Nishan

\section{Abstract}

In $21^{\text {st }}$ century while we still can't perform miracles in healing to maintain health, one Elixir is coming into the limelight is Placenta Extract which will aid magic in the era of wound healing. In other words, the Placenta act as various internal organs for the embryo, that's why it has a various medicinal effects, studies have shown magical effects of wound healing by use placentrex. A troublesome and usually unavoidable consequence of Head and Neck chemo radiation is oral mucositis which decreases patients' compliance and negatively influences the outcome of therapy by increasing overall treatment time. Currently, no single effective recommended treatment exists for this problem and a variety of supportive care measures have been practiced with limited benefits. While many study evaluated the therapeutic benefit of Placentrex in the management of oral mucositis seen in oral cancer patients undergoing treatment with concurrent chemoradiation. Even local injection of placentrex proved to be safe, cheap and effective in oral submucous fibrosis without any significant side effects and contra indication. The effect is long lasting. So can be given in early stages of OSMF with significant results. This review focuses on the use and benefits of placentrex in dentistry.

Keywords: Placentrex, Oral Surgery, Dentistry.

Copyright @ 2020: This is an open-access article distributed under the terms of the Creative Commons Attribution license which permits unrestricted use, distribution, and reproduction in any medium for non-commercial use (NonCommercial, or CC-BY-NC) provided the original author and source are credited.

\section{INTRODUCTION}

Use of placenta as a therapeutic agent has been prevalent for a long time. It is an immunologically privileged organ and has unique pharmacological effects like enhancement of wound-healing, antiinflammatory action, analgesic effect etc. A variety of substances with biological and therapeutic activity present in human placenta, have been isolated and identified as hormones, proteins, glycosaminoglycans, nucleic acids, polydeoxyribonucleotides (PDRNs) etc. The composition of placental extract thus depends on the method of its preparation. Consequently, it shows different therapeutic activities. In many countries, intramuscular and topical use of the extract for burn injuries, chronic wounds and as postsurgical dressing is an ageold practice.

Under such conditions, an effective tissueregenerative agent needs to take care of prevention of secondary bacterial or fungal infection. Recently, presence of biologically active NADPH and fibronectin type III like peptide in the extract has been demonstrated. Further, different spectroscopic and chromatographic analyses have revealed high degree of consistency among different batches of the extract [1].
Another form of attack the placenta uses is its various growth abilities, such as the ability to accelerate growth of the liver, as observed in the re-growth of cells and organs. This liver regenerative effect alone has been shown in animal testing to be effective for almost all diseases other than cancer, such as hepatitis, cirrhosis of the liver, heart disease, stroke, and renal failure. The placenta is now viewed by many as a substance which will revolutionise modern medicine.

Homeostasis works to create a balance between the nervous system, hormonal system and immunological system the Placenta increase the healing by stimulating the nervous regulation, hormonal regulation, \& immune system regulation and gives resistance to the body.

\section{Preparations of human placental extract}

Placental extracts can be classified into two different types: aqueous extract and hydroalcoholic extract. The components present in the extract depend on the method of its preparation and are based on solubility of the components in respective solvent of extraction. Thus, an aqueous extract is likely to contain 
more polar molecules such as peptides/proteins, small organic components like amino acids, nucleotides, polydeoxyribonucleotides (PDRNs), and carbohydrates and trace amount of lipids mostly bound to proteins which are comparatively soluble in aqueous medium. Likewise, various types of lipids may be present in hydroalcoholic extract (less polar and hydrophobic).

Chemical analysis of the hydroalcoholic extract revealed the presence of glycosphingolipids, cholesterol, triglycerides, high density lipoproteins, carbohydrates, sialic acids and others, including amino acids, nucleotides, carotenes, vitamins, including small amount of low-molecular-weight proteins/peptides containing hydrophobic amino acid residues which are soluble in a less polar solvent. Modern indigenous aqueous placental extract is prepared employing Filatov's procedure.

The manufacturing procedure of the indigenous extract holding confidentiality of the proprietary terms is as follows: fresh placentae were stored in ice and portions were tested for HIV antibody and Hepatitis B surface antigen. Single hot and cold aqueous extractions were done after incubating dissected and minced placenta at 900C and 60C respectively. This was followed by sterilization of the extract under saturated steam (pressure 15-lbs/sq inch at $1200 \mathrm{C}$ for $40 \mathrm{~min}$ ). After filtration and addition of $1.5 \%$ $(\mathrm{v} / \mathrm{v})$ benzyl alcohol as preservative, ampoules were filled and sterilized once again under the said condition for $20 \mathrm{~min}$. In the first sterilization, the extended duration of heat treatment essentially completed precipitation of a number of macromolecules like proteins.

Placenta is a maternofetal organ which is the primary site of nutrient and gas exchange between the fetus and the mother. Human Placenta is discoidal, haemochorial, chorioallantoic and deciduate. Is a union between developmental adenexa (extra-embryonic membranes and the uterine mucosa) for physiological exchange [2]. Main functions of the placenta are (a) exchange of metabolic and gaseous products between maternal and fetal bloodstreams and (b) production of hormones [3].

\section{The Placenta Acts as a Substitute for an Embryo's Organs}

The functions performed by the placenta in place of organs can be summarised as follows. As we can see, the placenta acts as an agent for various organs for the undeveloped embryo. We might call it an allpurpose organ.

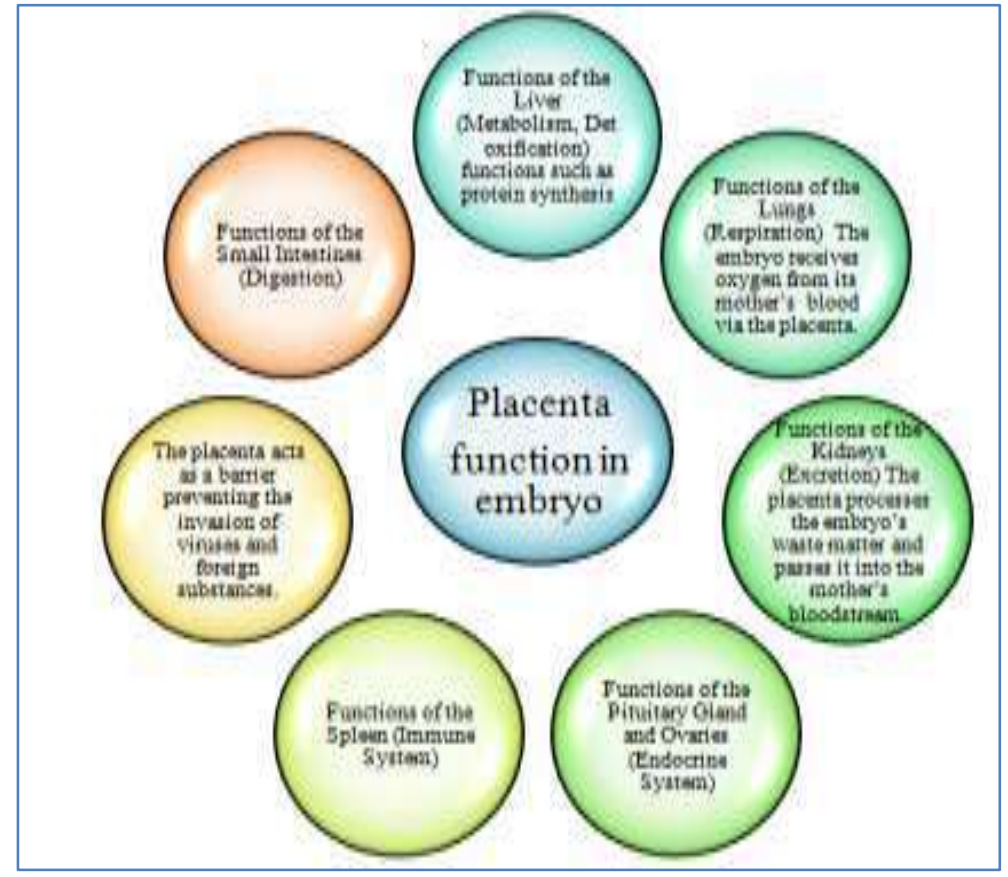

Fig-1: Functions of Placenta

\section{Growth factors of the placenta}

1. Hepatocyte Growth Factor (HGF): Promotes growth of liver parenchymal cells and various tissues.

2. Nerve Growth Factor (NGF): Promotes growth of nerve cells (sensory and sympathetic ganglionic cells).
3. Epidermal Growth Factor (EGF): Promotes growth of skin, lungs, cornea, and tracheal epithelial cells.

4. Fibroblast Growth Factor (FGF): Promotes growth of human fibroblasts, glia cells, and vascular endothelial cells. 
5. Insulin-like Growth Factor (IGF): Promotes growth of cartilage cells, and smooth muscle cells.

6. Colony-Stimulating Factor (CSF): Promotes growth of stem cells such as immunocompetent cell granulocytes, and macrophages.

7. Interleukin-1 (IL-1): Promotes production of immune-competent cells (T-cells, B-cells, and NK-cells),
8. Thymus cells and lymphokines.

9. Interleukin-2 (IL-2): Promotes growth of Tcells (helper T-cells, killer T-cells, and suppressor T-cells).

10. Interleukin-3 (IL-3): Promotes growth of hematopoietic cells, and mast cells.

11. Interleukin-4 (IL-4): Promotes growth of Bcells, and promotes division of antibodyproducing cells.

Table-1: Mechanism of placenta wound healing

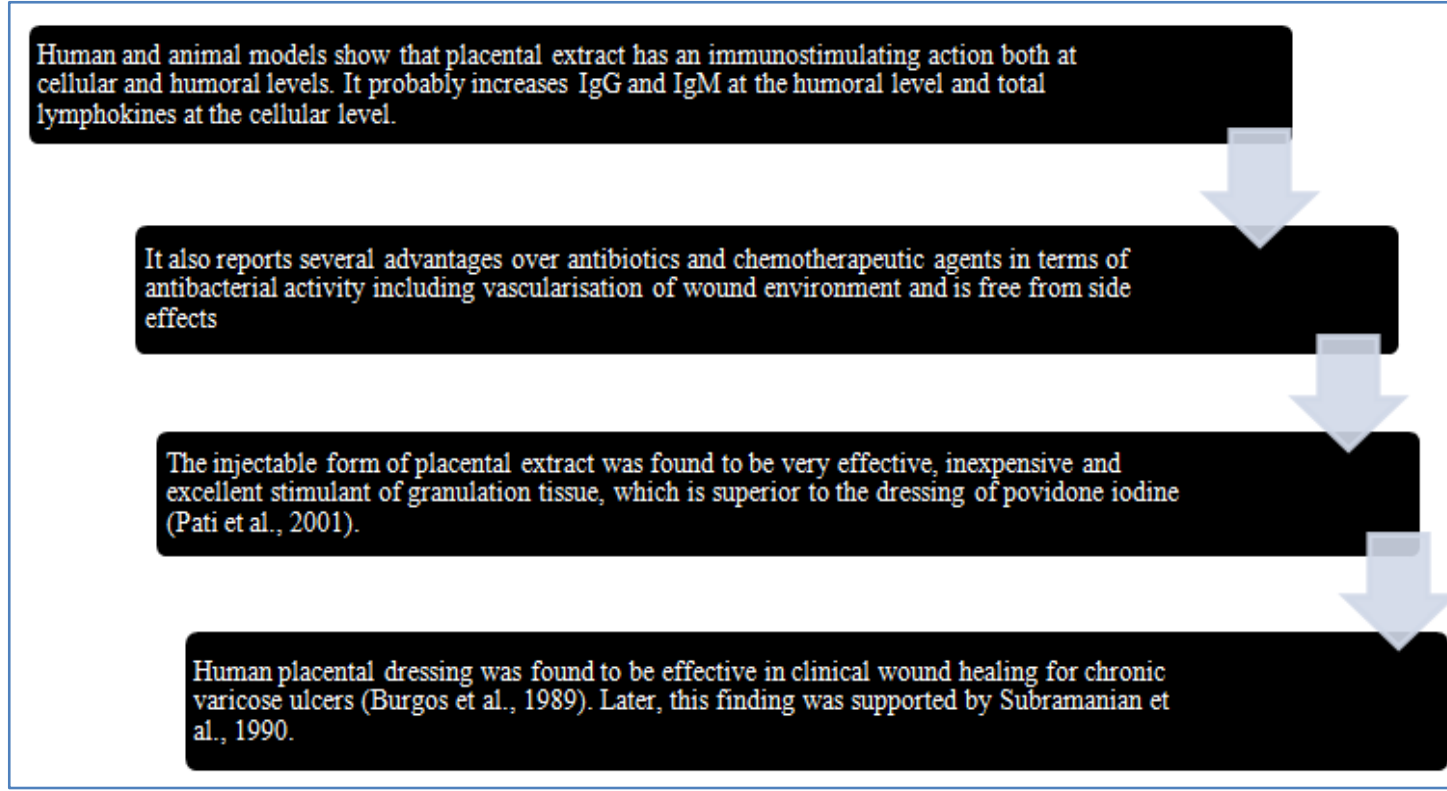

\section{Multiple therapeutic properties of aqueous extract of human placenta}

Several clinical investigations and findings have been reported on effective therapeutic use of placental extract such as clinical evaluation in radiationinduced oral mucositis [4] restorative effects in X-rayirradiated mice, for the treatment of myopic and senile chorio-retinal dystrophies [5] Human placenta has been described as an immunologically privileged organ [6] and its therapeutic effect was investigated first by Russian ophthalmologist, Filatov, who described the placental extract as a biogenic stimulator which could promote recovery of diseased tissues [7].

Placental possess analgesic, wound healing, and anti-inflammatory properties. Various biological products such as glycosaminoglycans, nucleic acids, polydeoxyribonucleotides, hormones, and proteins have been isolated from the placenta, suggesting its therapeutic potential as a wound healing agent (Chakraborthy and Bhattacharya, 2012; Vineeta et al. $[8,6]$

Further it has been demonstrated that one or more peptides from human placental extract including fibronectin type III stabilize trypsin activity after strong association, which is reversible in nature. Trypsin and similar proteolytic enzymes help in debridement and prevent keloid formation during wound healing and therefore regulation of its activity is an important criterion [9].

It is extremely effective in healing wounds as it increases the blood supply in tissues and enhances regeneration and recovery of the tissue [10].

Many authors demonstrated that placentrex with known tissue healing and regenerative properties can be considered in combination with other supportive care measures to overcome the problem of chemotherapy-induced mucositis thereby improve patients' chemoradiation to treatment $[4,11]$.

Placentrex has got immunotropic effect. Earlier Johansson RW. Naves suggested that placentrex exerts significant immunotropic effect as a when necessary on both humoral and cell medicated immunity, Increases total lymphocytes count as long as IgG and IgM levels significantly raised. From present study, it's also noticed that patients with mild and moderate grade responded well for local Inj. Placentrex. It was little difficult to inject in severe grade cases and in terms of burning sensation, colour of mucosa and fibrous bands results were not satisfactory, though trismus is relieved to some extent [12]. 
Other therapeutic effects of placental extract placenta can treat the following conditions

- Gynaecology: menopausal disorders, menstrual pain, irregular menstruation, failure of lactation, and high prolactin levels, etc.

- Internal Medicine: hepatitis, cirrhosis of the liver, chronic pancreatitis, diabetes, chronic gastritis, dyspepsia, gastric ulcers, duodenal ulcer, ulcerative colitis, bronchial asthma, chronic bronchitis, high blood pressure, low blood pressure, habitual constipation, and collagen disease,

- Surgery: chronic rheumatoid arthritis, osteoarthritis, arthritis, neuralgia, lumbago, and stiff shoulders, etc.

- Dermatology: atopic skin complaints, psoriasis, body odour, eczema, chapped skin, spots, and freckles, etc.

- Psychiatry: autonomic ataxia, and sleeplessness, etc.

- Urology: enlarged prostate, cystitis, and haemorrhoids, etc.

- Ophthalmology: cataracts, allergic conjunctivitis, and vision loss, etc.

- Ear, Nose and Throat: allergic rhinitis, Meniere's disease, and hay fever, etc.

- Dentistry: Periodontitis, and gum disease, etc.

\section{CONCLUSION}

Natural medicine continues to play an important role for prevention, alleviation and cure of diseases. In some part of the Western world, the use of traditional medicine has been largely lost. However, it is a widespread phenomenon in the developing countries where $80 \%$ of the population is still relying on traditional medicine for primary healthcare. Derived from folklore, human placental preparations show immense therapeutic value and can be safely used once it is ensured that the source is free from fatal infections like HIV, HBV, HCV and alike. The aqueous extract of human placenta is a scientifically proven potent wound healer. Characterization of active components present in different placental preparations and correlating them with their therapeutic actions are the promising avenue for future study.

\section{REFERENCES}

1. Chakraborty, P. D., \& Bhattacharyya, D. (2005). In vitro growth inhibition of microbes by human placental extract. Current Science, 782-786.
2. De, D., Chakraborty, P. D., Mitra, J., Sharma, K., Mandal, S., Das, A., \& Bhattacharyya, D. (2013). Ubiquitin-like protein from human placental extract exhibits collagenase activity. PLoS One, 8(3), e59585.

3. Marleau, A. M., Mcdonald, G., Koropatnick, J., Chen, C. S., \& Koos, D. (2012). Reduction of tumorigenicity by placental extracts. Anticancer research, 32(4), 1153-1161.

4. Kaushal, V., Verma, K., Manocha, S., Hooda, H. S., \& Das, B. P. (2001). Clinical evaluation of human placental extract (placentrex) in radiationinduced oral mucositis. International journal of tissue reactions, 23(3), 105-110.

5. Girotto, G., \& Malinverni, W. (1982). Use of placental extract for the treatment of myopic and senile chorio-retinal dystrophies. International journal of tissue reactions, 4(2), 169.

6. Vineeta, G., Aditya, S., Jithendra, K.D. (2016). Placental extract -the magical wound healer, Next milestone in the healing of periodontal surgery. IOSR J Dent Med Sci (IOSR-JDMS), 15, 73-9.

7. Filatov, V.P. (1955). Tissue Therapy. Foreign Language Publishing House, Moscow; 1955.

8. Chakraborty, P. D., \& Bhattacharyya, D. (2005). Isolation of fibronectin type III like peptide from human placental extract used as wound healer. Journal of Chromatography B, 818(1), 6773.

9. Chakraborty, P. D., \& Bhattacharyya, D. (2012). Aqueous extract of human placenta as a therapeutic agent. Recent Advances in Research on the Human Placenta. Rijeka, Croatia: InTech, 77-92.

10. Anil, S., \& Beena, V. T. (1993). Oral submucous fibrosis in a 12-year-old girl: case report. Pediatr Dent, 15(2), 120-2.

11. Kondaveeti, S. S., Divyambika, C. V., John, C., Manickavasagam, M., \& Rajendiran, S. (2018). Therapeutic Benefit of Placentrex in the Management of Acute Chemo Radiation Induced Mucositis in Oral Cancer Patients. Asian Pacific journal of cancer prevention: APJCP, 19(11), 3099.

12. Maher, R., Lee, A. J., Warnakulasuriya, K. A. A. S., Lewis, J. A., \& Johnson, N. W. (1994). Role of areca nut in the causation of oral submucous fibrosis: a case- control study in Pakistan. Journal of oral pathology \& medicine, 23(2), 65-69. 